\title{
Determinants of species richness, endemism and turnover in European longhorn beetles
}

\author{
Andrés Baselga \\ A. Baselga (baselga@mncn.csic.es), Dept de Biodiversidad y Biología Evolutiva, Museo Nacional de Ciencias Naturales - CSIC, c/José Gutiérrez \\ Abascal, 2, ES-28006 Madrid, Spain.
}

\begin{abstract}
This study assessed the diversity patterns of a large family of beetles, Cerambycidae, in Europe and tested the following hypotheses: 1) richness gradients of this hyperdiverse taxon are driven by water and energy variables; 2) endemism is explained by the same factors, but variation between areas also reflects post-glacial re-colonization processes; and 3) faunal composition is determined by the same climatic variables and, therefore, beta diversity (species turnover) is related to richness gradients. Species richness, endemism and beta diversity were modelled using inventories of 37 European territories, built from a database containing the distributions of 609 species. Area, spatial position, and nine topographical and climatic variables were used as predictors in regression and constrained analysis of principal coordinates modelling.

Species richness was mostly explained by a temperature gradient, which produced a south-to-north decreasing richness gradient. Endemism followed the same pattern, but was also determined by longitudinal variation, peaking in the southwestern and southeastern corners of the continent. Faunal turnover was explained by an important purely spatial pattern and a spatially structured environmental gradient. Thus, contrary to other groups, cerambycid richness was mostly explained by environmental energy, but not by water availability. Endemism was concentrated in the Iberian and Greek peninsulas, but not in Italy. Thus, the latter area may have been the major source of post-glacial re-colonization for European longhorn beetles or, otherwise, a poor refuge during glaciations. Turnover patterns were independent of the richness gradient, because northern faunas are nested in southern ones. Turnover, in contrast to richness, was driven by both the independent effects of climate and geographic constraints that might reflect dispersal limitation or stochastic colonization events, suggesting that richness gradients are more environmentally deterministic phenomena than turnover patterns.
\end{abstract}

Latitudinal richness gradients have been widely documented (Hillebrand 2004) and their causes thoroughly discussed (Hawkins et al. 2003, Willig et al. 2003, Currie et al. 2004, Evans and Gaston 2005, O’Brien 2006, Storch et al. 2006, Svenning and Skov 2007b, Mittelbach et al. 2007). On the other hand, much less research has been devoted to large-scale patterns of beta diversity, although several studies have addressed, for example, the turnover patterns of European butterflies (Dennis et al. 1998), Afrotropical birds (Williams et al. 1999), tropical floras (Tuomisto et al. 2003), American mammals (Rodríguez and Arita 2004) or temperate trees (Qian et al. 2005). Also, very recently Soininen et al. (2007) conducted a metaanalysis searching for relationships between different predictors and the decay of similarity with geographic distance across a wide range of organisms, ecosystems and geographical gradients. All these studies on richness and turnover patterns, with a few exceptions, are based on a small number of well-known taxonomic groups, such as vertebrates and plants, for which the coverage of distribution ranges is much more detailed than for the vast majority of biodiversity, notably invertebrates (Erwin 1991, Gaston 1991, Odegaard 2000). Although the large-scale patterns of richness gradients are, to present knowledge, quite coincident, several studies have reported poor correlation between richness of different taxonomic groups at landscape scales (Wolters et al. 2006), and exceptions to the large-scale richness gradients are also documented (see Willig et al. 2003, for a review). Therefore, the inclusion of invertebrates in research on large-scale diversity patterns is strongly needed.

The present study is linked to the conceptual background that considers richness patterns essentially driven by current climatic gradients (Hawkins et al. 2003, Whittaker et al. 2007), although it is acknowledged that historical factors such as past climate (Svenning and Skov 2007b), long-term climate stability (Hawkins et al. 2006) and postglacial re-colonization processes (Hewitt 2004, Svenning and Skov 2007a) might also influence the observed patterns. Similar considerations apply to endemism (Jansson 2003) and beta diversity (Graham 2006). However, the study of large-scale turnover patterns has only been 
addressed by a few papers that provide empirical descriptions of such patterns and assess the influence of geographic distance and climate on species turnover. The influence of past events on beta diversity has only been tested on a smaller, regional scale (Graham 2006).

Recent methodological advances have clarified the proper statistical tests for analyzing the variation in composition among assemblages (beta diversity) (Legendre et al. 2005) or the variation in beta diversity (Tuomisto and Ruokolainen 2006). Another methodological question, usually disregarded in the recent literature on beta diversity patterns, is the effect of richness gradients on our perception of faunal turnover. Although the topic is not new (Wilson and Shmida 1984, Williams et al. 1999), Koleff et al. (2003) recently clarified that the majority of recent papers on beta diversity use similarity indices that reflect both the turnover patterns and the richness gradients. However, if beta diversity is to be understood, richness gradients must be removed from the analyzed turnover patterns in order to disentangle both processes (Baselga 2007).

The present study focuses on diversity patterns of longhorn beetles (Coleoptera: Cerambycidae), one of the most diverse families of beetles, in Europe. Although data availability for this family is exceptional among invertebrates, it is still far from the spatial resolution which has been attained for vertebrates and plants. This study aims to assess the interrelation between richness, endemism, and turnover, and between the diversity patterns and current environmental gradients or broad-scale spatial constraints that could reflect historical diversification processes, dispersal limitation, or stochastic colonization events. Therefore, a spatially explicit analysis was performed, searching for the pure effects of environment or spatial position, and the shared effects of the spatially structured environmental gradients (Borcard et al. 1992). The rationale is that spatial variables submitted after environmental ones can aid in detection of effects that have not been accounted for, such as geographical or historical effects (Legendre and Legendre 1998). Several hypotheses were specifically tested: 1) richness gradients are driven by water and energy variables, as has been found in other taxonomic groups (Hawkins et al. 2003); 2) temperature is the most relevant determinant of Cerambycidae richness patterns in European latitudes, due to their ectothermic physiology; 3) endemism is explained by the same factors, but the pattern has a more marked spatial structure due to the effect of historical events; and 4) faunal composition is determined by the same climatic variables and, therefore, species turnover correlates with richness gradients.

\section{Methods}

\section{Biological data}

The study area included continental Europe. Thirty-seven inventories of Cerambycidae were obtained from Danilevsky (2007). In general, these inventories refer to European countries, but some countries were split based on biogeographical criteria. European Russia was divided in three territories (northern, central and southern) due to its extremely large area, and Crimea was separated from
Ukraine. Bosnia and Croatia were included in a single check-list and only the European part of Turkey was considered. For simplicity, all these territorial units are hereafter referred to as "countries". Islands were excluded from this study to avoid insularity effects which could confound general patterns of diversity. In total, 609 species of longhorn beetles were included in this study, and each inventory ranged from 73 (Denmark) to 301 species (Greece), with a mean of $175.1 \pm 65.6$ SD.

\section{Predictor variables}

Three sets of variables were obtained for each country: 1) area; 2) spatial position: mean, minimum and maximum longitude (Long, Long min , Long max $_{\text {ax }}$ ) and mean, minimum and maximum latitude (Lat, Lat $\left.\min _{\min }, \mathrm{Lat}_{\max }\right)$; and 3) environmental factors: mean altitude (Alt); altitudinal range (Alt $\left.t_{\text {ran }}\right)$; annual mean temperature $\left(\mathrm{T}_{\mathrm{ann}}\right)$; spatial range of $\mathrm{T}_{\mathrm{ann}}\left(\mathrm{T}_{\mathrm{ran}}\right)$; maximum temperature of the warmest month $\left(\mathrm{T}_{\max }\right)$; minimum temperature of the coldest month $\left(\mathrm{T}_{\min }\right)$; annual precipitation $\left(\mathrm{P}_{\text {ann }}\right)$; spatial range of $\mathrm{P}_{\text {ann }}\left(\mathrm{P}_{\mathrm{ran}}\right)$; precipitation of driest quarter $\left(\mathrm{P}_{\mathrm{dri}}\right)$; and spatial range of $\mathrm{P}_{\mathrm{dri}}\left(\mathrm{P}_{\mathrm{drn}}\right)$. Topographic and climatic variables were obtained from Worldclim 1.4 layers (Hijmans et al. 2005). Thereafter, mean or range values for each country were extracted from a European GIS database (0.08 degrees resolution) using IDRISI (Clark Labs 2000), together with their respective areas $\left(\mathrm{km}^{2}\right)$ and geographical coordinates (latlong).

\section{Analytical methods}

The relationship between the aforementioned predictors and richness, endemism, and beta diversity of European Cerambycidae was assessed.

1) Richness. Multiple relationships between species richness and the explanatory variables were analysed using regression modelling (Legendre and Legendre 1998) performed with Statistica 6.0 (StatSoft). Richness was log transformed to normalize model residuals. Linear, quadratic and cubic functions of the predictors were independently regressed against the response variable to determine significant relationships. Significant terms for each set (area, environment, and spatial variables) were selected by means of a backward stepwise procedure. Finally, variation partitioning among sets of predictors was used to quantify the relative importance of the pure effects of area (A), environment (E) and spatial variables (S), and their respective shared influences (Legendre and Legendre 1998). Such an approach allows non-independent explanatory variables to be dealt with, as it is explicitly designed to identify the portions of explained variability that are shared by different sets of variables and those that are independent (Borcard et al. 1992). Area is included as a covariable in order to control for the effect of differences in area among sampling units. Moreover, to confirm the robustness of the richness patterns regarding the variation in country area, a second analysis was performed using species density (Whittaker et al. 2001) as a dependent variable (computed as the fraction between the logarithm of richness and the logarithm of area). Since the number of cases is not high, 
the robustness of all $\mathrm{A}, \mathrm{E}$ and $\mathrm{S}$ models was assessed by estimating the $\mathrm{SE}$ of all $\mathrm{R}^{2}$ and $\mathrm{F}$ values by means of bootstrap resampling performed with PopTools (Hood 2006)

2) Endemism. A measure of the uniqueness of the fauna of each country was computed as the number of endemic species with a distribution range $<6 \times 10^{5} \mathrm{~km}^{2}$ (category IV by Lumaret and Lobo 1996). Since the available data notes the presence of a species in each country, the areas of all countries where a species was recorded were combined to estimate its distribution range. Scores of endemism were log transformed to normalize model residuals and regressed against the predictors following the same procedure as described for richness, including the use of density of endemics in a second analysis and the bootstrap analysis.

3) Beta diversity. Faunal heterogeneity among countries was analyzed with the Simpson's index of beta diversity $\left(\beta_{\text {sim }}\right)$ and the resulting dissimilarity matrix was used to assess compositional differences due to its independence of species richness gradients (Koleff et al. 2003). Ordination of European countries was based on this faunal dissimilarity matrix, which was submitted to a nonparametric multidimensional scaling analysis (NMDS, Legendre and Legendre 1998) performed with Statistica 6.0 (StatSoft). The number of dimensions could not be selected using a scree-plot procedure, because stress values decreased gradually from 0.23 (two dimensions) to 0.09 (nine dimensions). Therefore, nine dimensions were extracted, using 0.1 as the cut-off point of acceptable stress. Axes scores for the 37 countries were submitted to a cluster analysis to identify the major groups of faunas. A dendrogram was drawn with Statistica 6.0, taking Euclidean distance as the measure of resemblance and average linkage procedure as the linkage rule. Significance of the faunal groups yielded by the cluster analysis was assessed by means of ANOSIM tests computed in R ( $\mathrm{R}$ Development Core Team 2006) using the vegan package (Oksanen et al. 2007).

Thereafter, the variables determining the described patterns were explored. A constrained analysis of principal coordinates (CAP) was computed in $\mathrm{R}$ using the vegan package (Oksanen et al. 2007) to examine the relationship between variability in the table of species occurrences and the three sets of predictor variables. CAP was selected because it can be computed with any dissimilarity index with ecological significance and, therefore, $\beta_{\text {sim }}$ dissimilarity was preserved in the constrained ordination. Area, the nine aforementioned environmental variables, and spatial variables (the nine terms of a third degree polynomial of mean latitude and longitude; trend surface analysis, Legendre and Legendre 1998) were used as predictors to perform constrained ordinations yielding respectively $\mathrm{A}, \mathrm{E}$ and $\mathrm{S}$ models. Since the order of inclusion in the model affects the significance computed by the permutation tests (vegan command permutest; Oksanen et al. 2007), the amount by which the explained variation was reduced due to the elimination of a single variable (compared with the complete model) was tested prior to the final analysis. This allowed the individual variables to be ranked in order of their independent contribution to the total variation in the response variable (from greatest to least), and the variables were included in the significance test in this order.
Only significant variables were retained $(p<0.05)$ to avoid overfitting due to the inclusion of non-significant terms. Finally, to partition the variation among A, E and $S$ sets of predictors, partial CAPs were performed, eliminating the effects of each variable (covariable) on the others, yielding estimates of pure effects (Borcard et al. 1992).

\section{Results}

\section{Richness}

Species richness formed a clear latitudinal gradient (Fig. 1a), significantly related to a number of variables (Table 1). While area, altitudinal range, range of precipitation and temperature variables showed positive relationships, latitudinal variables were negatively related to richness, and mean altitude presented a quadratic relationship with the highest richness at intermediate altitudes. A $\log$ model of area (A) accounted for small percentage of the variation, and the models of environmental (E) and spatial (S) variables were comprised, respectively, of Alt ran and $\mathrm{T}_{\max }$, and $\mathrm{Lat}_{\min }$ (Table 1). The independent effects of the $\mathrm{A}, \mathrm{E}$ and $\mathrm{S}$ models were negligible, but they shared important portions of the explained variance, especially $\mathrm{E}$ and S (Fig. 2a). The bootstrap analysis showed that the parameters and significance of $\mathrm{E}$ and $\mathrm{S}$ models were robustly estimated, while the bootstrap estimates for the A model were much more variable (Table 1). Similar results were obtained using species density as a dependent variable. However, some individual predictors presented slightly different relationships (Supplementary material, Table S1 and Fig. 2b).

\section{Endemism}

The presence of endemics was concentrated in southern Europe (Fig. 1b). Although a positive and significant Pearson correlation was found between $\log$ transformed endemism and species richness $(\mathrm{R}=0.51, \mathrm{t}=3.48, \mathrm{p}=$ $0.001)$, different spatial and environmental variables were found to be significantly related with endemism (Table 2). Temperature variables showed a positive relationship, whereas longitudinal, latitudinal and altitudinal variables presented polynomial relationships with endemism, with the highest scores at low and high values of longitude, at low values of latitude and intermediate values of altitude. Environmental (E) and spatial (S) models were comprised of Alt, Alt $_{\mathrm{ran}}, \mathrm{T}_{\mathrm{ran}}, \mathrm{T}_{\min }$ and $\mathrm{T}_{\max }$, and the quadratic functions of Long, Long ${ }_{\text {min }}$, Lat, Lat ${ }_{\text {min }}$ and $\mathrm{Lat}_{\text {max }}$, respectively (Table 2). The pure effect of environmental variables was small compared to the purely spatial effect, but the greatest part of the variance was explained by the joint effect of both sets of variables (Fig. 2c). The bootstrap analysis indicated that these results wer quite robust (Table 2 and Supplementary material, Table S2). A supplementary analysis using density of endemics as a dependent variable yielded almost identical results (Supplementary material, Table S2, Fig. 2d). 

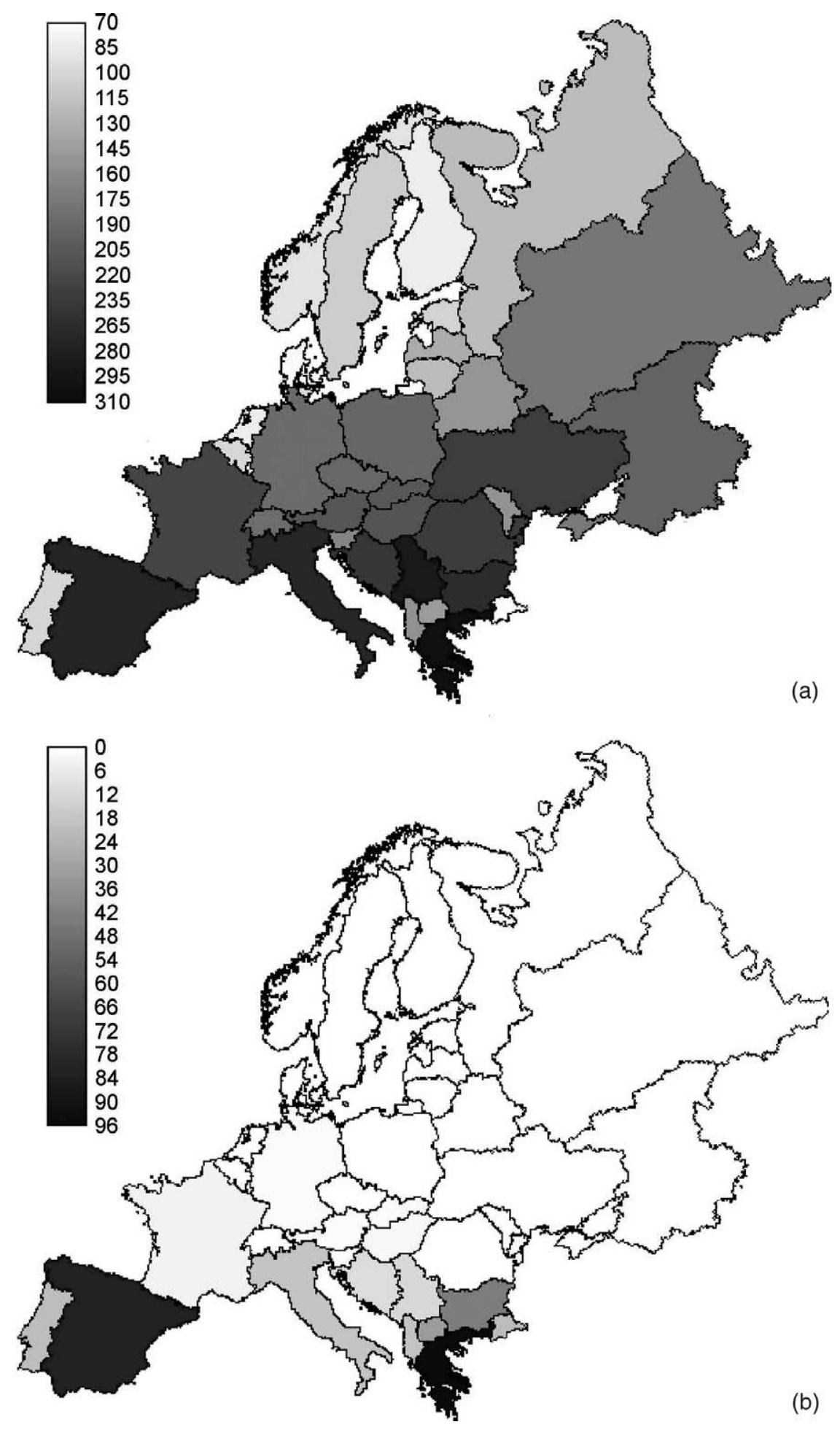

Fig. 1. Study area and scores of (a) species richness and (b) endemism in the territories considered as sampling units.

\section{Beta diversity}

The dendrogram built using the scores of the 9 NMDS axes (stress $=0.095)$ showed the presence of three major faunal regions among continental European countries (Fig. 3): 1) the Iberian peninsula; 2) Albania, Macedonia, Greece,
Bulgaria and European Turkey; and 3) the rest of Europe (ANOSIM R $=0.82, \mathrm{p}<0.001$ ). The latter group could be divided into three subgroups: 3a) northern European countries plus some central European countries such as Germany and Austria; 3b) central and southern European countries from France to Moldova; and 3c) Serbia, southern 
Table 1. Relationships between predictors and species richness, and models for each group of variables. The sign of the relationships and percentage of explained variance $\left(\mathrm{R}^{2}\right)$ are shown. $\mathrm{A}, \mathrm{S}$ and $\mathrm{E}$ are the area, spatial and environmental models, respectively. The bootstrap SE values for the model parameters are given in parentheses.

\begin{tabular}{|c|c|c|c|c|c|}
\hline Variable & Function (sign) & $\mathrm{R}^{2}(\%)$ & $\mathrm{F}$ & DF & $\mathrm{p}$ \\
\hline Area & $\log (+)$ & 10.9 & 4.28 & 1,35 & 0.046 \\
\hline Long & $\mathrm{ns}$ & 1.8 & 0.64 & 1,35 & 0.430 \\
\hline Long $_{\min }$ & ns & 1.5 & 0.52 & 1,35 & 0.474 \\
\hline Long $_{\max }$ & ns & 1.3 & 0.46 & 1,35 & 0.502 \\
\hline Lat & linear $(-)$ & 33.6 & 17.73 & 1,35 & $<0.001$ \\
\hline Lat $_{\min }$ & linear $(-)$ & 43.7 & 27.21 & 1,35 & $<0.001$ \\
\hline Lat $_{\max }$ & linear $(-)$ & 25.9 & 12.23 & 1,35 & 0.001 \\
\hline Alt & quadratic $(+,-)$ & 25.2 & 5.74 & 2,34 & 0.007 \\
\hline $\mathrm{Alt}_{\mathrm{ran}}$ & linear $(+)$ & 36.5 & 20.08 & 1,35 & $<0.001$ \\
\hline $\mathrm{T}_{\mathrm{ann}}$ & linear $(+)$ & 14.0 & 5.70 & 1,35 & 0.022 \\
\hline $\mathrm{T}_{\text {ran }}$ & linear $(+)$ & 29.3 & 14.51 & 1,35 & 0.001 \\
\hline $\mathrm{T}_{\max }$ & linear $(+)$ & 29.5 & 14.62 & 1,35 & 0.001 \\
\hline $\mathrm{T}_{\min }$ & ns & 2.7 & 0.98 & 1,35 & 0.329 \\
\hline$P_{a n n}$ & ns & 0.0 & 0.01 & 1,35 & 0.931 \\
\hline$P_{\text {ran }}$ & linear $(+)$ & 10.9 & 4.28 & 1,35 & 0.046 \\
\hline$P_{\text {dri }}$ & ns & 0.0 & 0.00 & 1,35 & 0.947 \\
\hline$P_{d r n}$ & linear $(+)$ & 16.3 & 6.79 & 1,35 & 0.013 \\
\hline Model for A & log Area & $10.9(9.5)$ & $4.28(5.08)$ & 1,35 & $0.046(0.214)$ \\
\hline Model for $\mathrm{E}$ & Alt $\mathrm{O}_{\text {ran }}+\mathrm{T}_{\max }$ & $55.6(11.05)$ & $21.29(12.44)$ & 2,34 & $<0.001(6.5 \mathrm{E}-06)$ \\
\hline Model for S & Lat $_{\min }$ & $43.7(13.52)$ & $27.21(19.90)$ & 1,35 & $<0.001(0.006)$ \\
\hline Model $\mathrm{A}+\mathrm{E}+\mathrm{S}$ & $\log$ Area + Alt $_{\text {ran }}+\mathrm{T}_{\max }+$ Lat $_{\min }$ & $57.3(11.21)$ & $10.72(7.56)$ & 4,32 & $<0.001(0.002)$ \\
\hline
\end{tabular}

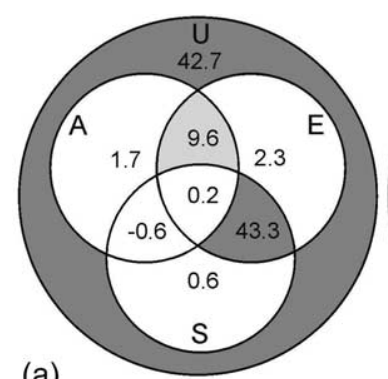

(a)
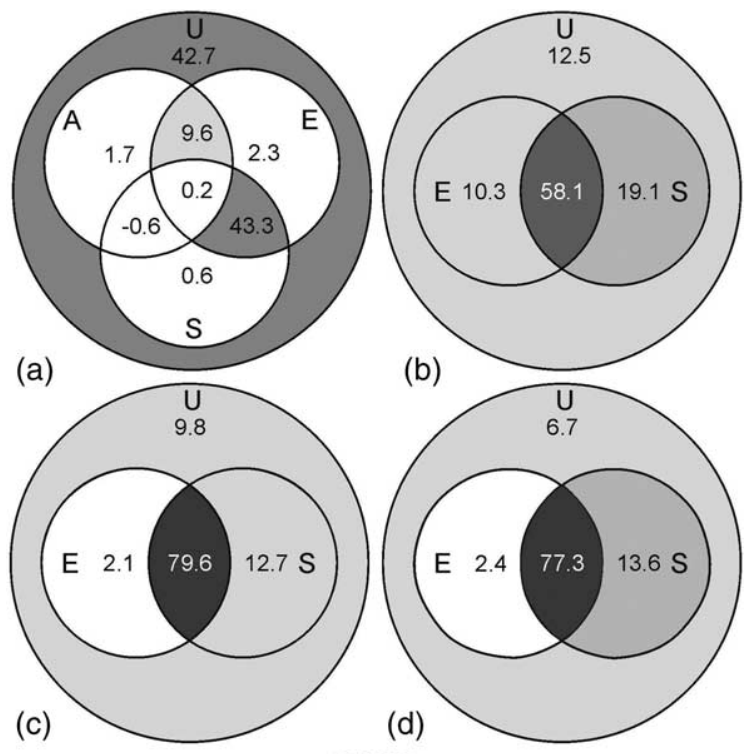

(b)
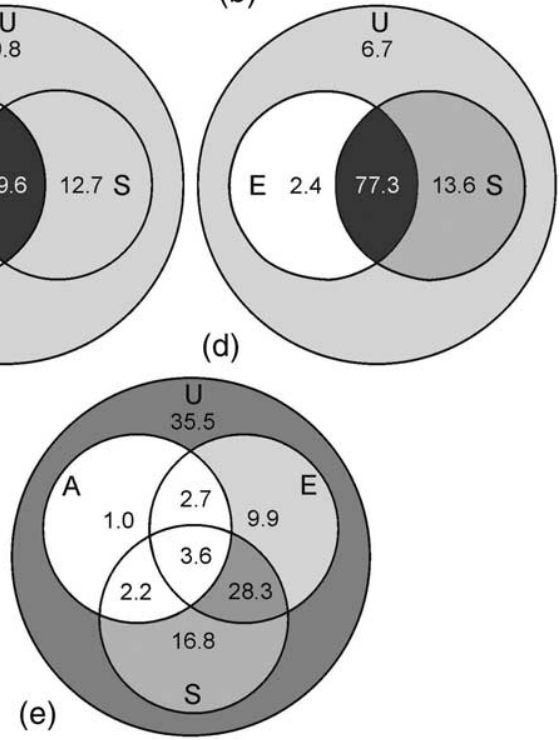

Fig. 2. Partitioning of the variation (\%) in (a) richness, (b) species density, (c) endemism, (d) endemics density and (e) faunal composition, among groups of explanatory variables, $\mathrm{A}=$ area, $\mathrm{E}=$ environment and $\mathrm{S}=$ spatial variables. $\mathrm{U}$ is the unexplained fraction. Grey tones are proportional to the amount of explained variation.
Russia and Crimea (ANOSIM $\mathrm{R}=0.69, \mathrm{p}<0.001$ ). Faunal composition showed no significant relationship with species richness (pseudo- $\mathrm{F}=0.85, \mathrm{p}=0.272$ ) or the logarithm of species richness (pseudo- $\mathrm{F}=0.88, \mathrm{p}=0.224$ ) but, in contrast, $24 \%$ of the variation in composition (beta diversity) was explained by endemism (log-transformed scores) (pseudo-F $=8.04, \mathrm{p}<0.001$ ). The assessment of the predictors explaining beta diversity yielded significant contributions of the three sets of variables considered (A, $\mathrm{E}$ and $\mathrm{S}$ models). Area, mean altitude, minimum and maximum temperature, annual precipitation and range of precipitations and all terms of the third degree polynomial of mean longitude and latitude (with exception of Long ${ }^{2} \times$ Lat) turned out to be significantly related to beta diversity (Table 3). Among the latter, only the five terms (Lat ${ }^{2}$, Lat, $\mathrm{Lat}^{3}$, Long and Long ${ }^{3}$ ) explaining a greater portion of variance were selected, in order to avoid spurious interpretations due to unbalanced comparison of models built with different numbers of predictors. Partitioning of the variation showed that the pure effect of $\mathrm{A}$ was nonsignificant (pseudo- $F=0.69, p=0.759$ ), leaving the greatest part of the variation attributed to area in the fractions shared with $\mathrm{E}$ and $\mathrm{S}, \mathrm{G}$ or both models (Fig. 2e). On the contrary, pure effects of $\mathrm{E}$ (pseudo- $\mathrm{F}=1.40, \mathrm{p}=0.039$ ) and $S$ (pseudo- $F=2.36, p<0.001$ ) were significant and moderately important, especially the pure spatial fraction (Fig. 2e). However, the greatest portion of variation was explained again by the joint effect of environmental and geographical sets of variables (Fig. 2e). The variables that remained significant in the partial models and thus were responsible for the pure effect of each set of predictors were Long, Lat and Long ${ }^{3}$ among the spatial variables, while none were detected among the environmental variables, although pure environmental fraction was found to be statistically significant, as mentioned above. 
Table 2. Relationships between predictors and endemism, and models for each group of variables. The sign of the relationships and percentage of explained variance $\left(\mathrm{R}^{2}\right)$ are shown. $\mathrm{A}, \mathrm{S}$ and $\mathrm{E}$ are the area, spatial and environmental models, respectively. The bootstrap $\mathrm{SE}$ values for the model parameters are given in parentheses. $f^{2}$ is the quadratic function of the variable considered.

\begin{tabular}{|c|c|c|c|c|c|}
\hline Variable & Function (sign) & $\mathrm{R}^{2}(\%)$ & $\mathrm{F}$ & DF & $\mathrm{p}$ \\
\hline Area & ns & 0.4 & 0.15 & 1,35 & 0.701 \\
\hline Long & $\operatorname{cubic}(-,+,-)$ & 21.5 & 3.01 & 3,33 & 0.044 \\
\hline Long $_{\min }$ & cubic $(-,+,-)$ & 24.9 & 3.64 & 3,33 & 0.023 \\
\hline Long $_{\max }$ & ns & 3.9 & 1.42 & 1,35 & 0.241 \\
\hline Lat & quadratic $(-,+)$ & 87.7 & 120.74 & 2,34 & $<0.001$ \\
\hline Lat $_{\min }$ & quadratic $(-,+)$ & 78.6 & 62.55 & 2,34 & $<0.001$ \\
\hline Lat $_{\max }$ & quadratic $(-,+)$ & 79.4 & 65.42 & 2,34 & $<0.001$ \\
\hline Alt & quadratic $(+,-)$ & 32.7 & 8.25 & 2,34 & 0.001 \\
\hline $\mathrm{Alt}_{\mathrm{ran}}$ & quadratic $(+,-)$ & 23.7 & 5.29 & 2,34 & 0.010 \\
\hline $\mathrm{T}_{\mathrm{ann}}$ & linear $(+)$ & 55.9 & 44.32 & 1,35 & $<0.001$ \\
\hline $\mathrm{T}_{\text {ran }}$ & linear $(+)$ & 14.2 & 5.79 & 1,35 & 0.022 \\
\hline$T_{\max }$ & linear $(+)$ & 57.1 & 46.57 & 1,35 & $<0.001$ \\
\hline $\mathrm{T}_{\min }$ & linear $(+)$ & 38.5 & 21.92 & 1,35 & $<0.001$ \\
\hline$P_{\text {ann }}$ & ns & $<0.1$ & $<0.01$ & 1,35 & 0.979 \\
\hline$P_{r a n}$ & ns & 3.6 & 1.32 & 1,35 & 0.258 \\
\hline$P_{d r i}$ & ns & 4.6 & 1.67 & 1,35 & 0.205 \\
\hline$P_{d r n}$ & ns & 2.3 & 0.81 & 1,35 & 0.375 \\
\hline Model for $\mathrm{E}$ & Alt + Alt $t_{\text {an }}+T_{\text {ran }}+T_{\min }+T_{\max }$ & $81.7(5.2)$ & $27.73(15.78)$ & 5,31 & $<0.001(5.8 \mathrm{E}-07)$ \\
\hline Model for S & $\begin{array}{l}\mathrm{f}^{2} \text { Long }+\mathrm{f}^{2} \text { Long }_{\min }+\mathrm{f}^{2} \text { Lat }+ \\
\mathrm{f}^{2} \text { Lat }_{\min }+\mathrm{f}^{2} \text { Lat }_{\max }\end{array}$ & $92.3(1.7)$ & $41.81(24.40)$ & 8,28 & $<0.001(6.4 \mathrm{E}-11)$ \\
\hline Model for $\mathrm{E}+\mathrm{S}$ & $\begin{array}{l}\text { Alt }+ \text { Alt }_{\text {ran }}+\mathrm{T}_{\text {ran }}+\mathrm{T}_{\min }+\mathrm{T}_{\max }+ \\
\mathrm{f}^{2} \text { Long }+\mathrm{f}^{2} \text { Long } \\
\mathrm{f}^{2} \text { Lat }_{\min }+\mathrm{f}^{2}+\mathrm{f}^{2} \text { Lat } \text { Lat }_{\max }\end{array}$ & $94.4(1.3)$ & $23.51(316.4)$ & 15,21 & $<0.001$ (1.9E-09) \\
\hline
\end{tabular}

\section{Discussion}

Our knowledge about European diversity patterns is based mainly on some well-known taxonomic groups, especially vertebrates and plants (Rodríguez et al. 2005, 2006, Svenning and Skov 2007b, Montoya et al. 2007, Whittaker et al. 2007) and some invertebrates such as butterflies (Hawkins and Porter 2003). The coarse gradients of richness and endemism across Europe are quite coincident, but surrogacy cannot be assumed, both because the variables driving gradients perform unevenly for different taxa (Whittaker et al. 2007), and especially because of differences in the turnover patterns of different groups. Turnover patterns are highly influenced by 1) the differential dispersal capacities of each group, which are thus in different degrees of equilibrium with current climate (Araujo and Pearson 2005); and 2) the historical (and thus probably highly contingent) processes of re-colonization of deglaciated areas, which have taken place in diverse ways for different groups (Hewitt 1999). For this reason, research on hyperdiverse invertebrate taxa should be considered crucial for our understanding of biodiversity patterns, although complete inventories at a grain size similar to that used in recent studies of plant and vertebrate patterns (Svenning and Skov 2007b, Whittaker et al. 2007) are currently unavailable for almost any group of invertebrates. However, the assessment

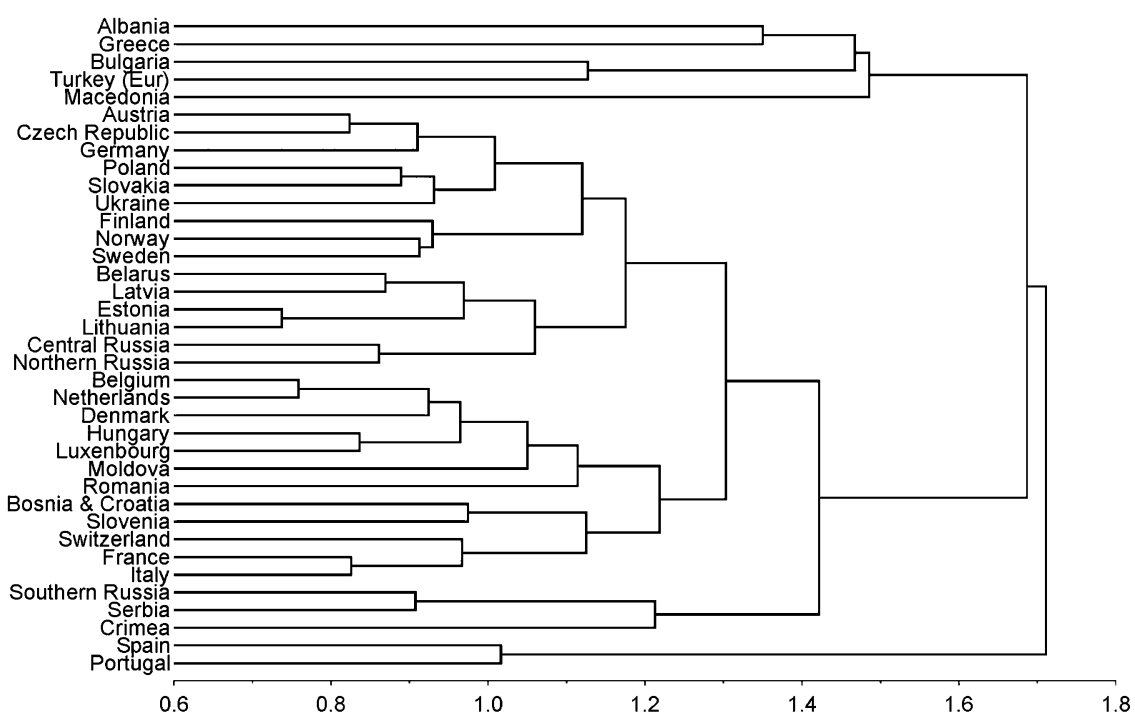

Fig. 3. Classification tree of the European countries based on Cerambycidae species composition. Euclidean distance computed from the scores of the NMDS was used as distance measure and the average linkage method as the linkage rule. 
Table 3. Relationships between predictors and beta diversity, and models for each group of variables. Percentage of variation explained (inertia) are shown. A, S and E are the area, spatial and environmental models, respectively.

\begin{tabular}{lrrr}
\hline Variable & Variation $(\%)$ & Pseudo-F & \multicolumn{1}{c}{$\mathrm{p}$} \\
\hline Area & 9.5 & 2.61 & 0.005 \\
Long & 6.4 & 4.45 & 0.003 \\
Long $^{2}$ & 5.8 & 4.00 & 0.002 \\
Long $^{3}$ & 5.8 & 4.06 & 0.003 \\
Lat $^{2}$ & 5.2 & 3.63 & 0.001 \\
Lat $^{2}$ & 32.1 & 22.33 & $<0.001$ \\
Lat $^{3}$ & 3.4 & 2.33 & 0.034 \\
Long $^{2}$ Lat & 5.0 & 3.50 & 0.002 \\
Long $^{2} \times$ Lat $^{2}$ & 3.3 & 2.33 & 0.031 \\
Long $\times$ Lat $^{2}$ & 1.0 & 0.70 & 0.539 \\
Alt & 4.7 & 3.2 & 0.018 \\
Alt & 0.9 & 0.7 & 0.617 \\
$\mathrm{~T}_{\text {ann }}$ & 1.1 & 0.8 & 0.534 \\
$\mathrm{~T}_{\text {ran }}$ & 0.9 & 0.6 & 0.730 \\
$\mathrm{~T}_{\text {max }}$ & 4.4 & 3.1 & 0.014 \\
$\mathrm{~T}_{\text {min }}$ & 18.7 & 13.0 & $<0.001$ \\
$\mathrm{P}_{\text {ann }}$ & 4.1 & 2.9 & 0.009 \\
$\mathrm{P}_{\text {ran }}$ & 2.6 & 1.8 & 0.100 \\
$\mathrm{P}_{\text {dri }}$ & 2.6 & 1.8 & 0.090 \\
$\mathrm{P}_{\text {drn }}$ & 3.7 & 2.6 & 0.024 \\
Model for A & 9.5 & 2.61 & 0.005 \\
Model for E & 44.5 & 4.01 & $<0.001$ \\
Model for S & 50.9 & 5.18 & $<0.001$ \\
Model A $+\mathrm{E}+\mathrm{S}$ & 64.6 & 4.13 & $<0.001$ \\
\hline
\end{tabular}

of diversity gradients is scale-dependent and for this reason the explanatory power of variables depends on the grain size (Rahbek and Graves 2001). For this reason, as pointed out by Blackburn and Gaston (2002), "studies at all scales have the potential to inform about the structure and function of the ecological systems". The present results highlight that coarse sample units allow for the assessment of major diversity patterns of European longhorn beetles, and that the environmental and spatial relationships modelled in this study are robust despite the relatively low number of cases, as demonstrated by the bootstrap analyses. Therefore, similar attempts could be developed for other invertebrates.

\section{Richness patterns, similarities and differences with other taxa}

The partitioning of the effects of area, environment, and spatial position on species richness shows a negligible pure effect of country area, with the greatest part of the variance explained by area attributed to the fraction shared with environment. This result is reinforced by the analysis of species density, which yielded similar results, suggesting that the described biodiversity patterns are not biased by differences in sampling unit areas. Therefore, controlling for the effect of different areas and among European countries, the latitudinally structured gradient of temperature is the driving determinant of the richness pattern, whereas precipitation appears to have negligible influence on it. It seems that, considering the extent of Europe and this coarse scale analysis, Cerambycidae richness is controlled by energy, while water is a non-limiting resource. This result was also suggested for dung beetles at a regional scale (Lobo et al. 2002), but is quite different from results found for European vertebrates, plants and butterflies (Hawkins and Porter 2003, Hawkins et al. 2003, Whittaker et al. 2007) in which water always has a role in the richness models. In contrast, longhorn beetles seem to manage well with aridity in southern Europe. Thus, I hypothesize that the threshold below which richness could be controlled by water availability is located in more southern latitudes.

\section{Endemism, history and its relation with richness}

Endemism is highly related to history since long-term climatic stability is supposed to cause increments in the number of endemisms (Jansson 2003), because unstable areas with greater amplitude of climatic shifts are affected more by extinction events (Willis and Niklas 2004) and distribution range movements that have prevented isolation and thus speciation (Ribera and Vogler 2004). In Europe, Pleistocene glacial refugia are both sources of re-colonization (Hewitt 1999) and centres of speciation (Ribera and Vogler 2004). Therefore, "stable areas" were the nonglaciated regions, and the pattern could thus be seen as more of a qualitative relationship than a quantitative relationship with stability; the glaciated areas seem to have lost their pre-glacial endemics, whereas the non-glaciated regions have conserved them. This fact was shown on a regional scale (Alps) for the number of endemic vascular plants, which is strongly correlated with the degree of glaciation (proportion of inhabitable area) during the Last Glacial Maximum (Tribsch 2004). For this reason, endemism of European Cerambycidae, like richness, presents its highest values in the south, although the spatially structured gradient is even more marked. In other words, the effect of glaciations probably produces a strong covariation between current climate and historic patterns, causing endemism and richness gradients to be correlated.

Despite the correlation of the south-north gradients, endemism of European longhorn beetles is also clearly explained by a non-linear relation with longitude, contrary to richness. Endemic species are concentrated in the Iberian and Greek peninsulas, but are much less abundant in the Italian peninsula. Considering that species richness is not reduced in Italy, two possibilities could explain the observed low endemism: 1) Italy has suffered more ice age extinctions than the two other areas, and present richness was achieved later by colonization; or 2) a lower degree of isolation of the Italian longhorn beetles during the Pleistocene period enabled Italian paleofauna to expand their distribution to northern countries, while endemic species have been conserved in their restricted ranges on the Iberian and Greek peninsulas. Both hypotheses are testable through the genetic structures of Cerambycidae populations (Hewitt 1999, 2004), but hypothesizing that the Italian refugium was the most frequent source of postglacial re-colonization for longhorn beetles seems more parsimonious as a primary hypothesis than introducing the historic explanation of a two-step extinction and north-south re-colonization processes. Although classical paradigms tend to consider Balkan-Greek and Iberian regions as major sources of recolonization, with the Italian refuge blocked by the Alps (Hewitt 1999, 2004), new studies have found different situations involving different dispersal centres (i.e. Habel 
et al. 2005). For longhorn beetles, recolonization from Italian populations may have been particularly important.

\section{Disentangling beta diversity from richness gradients}

Beta diversity patterns of European Cerambycidae are independent from richness gradients. The selection of a turnover measure (Simpson's index) not biased by richness variations (Koleff et al. 2003) allows affirmation a priori that richness gradients are not biasing present results (Baselga 2007). Besides the methodological independence between turnover and richness measures, the results of this study show that there is no real covariation between richness and turnover of longhorn beetle faunas. Such independence may be because northern, less diverse faunas are the consequence of post-glacial re-colonization from the southern refugia. In fact, northern assemblages are the same faunas, but just with less species or, in other words, northern faunas are nested in southern ones. The independence between turnover and richness is related also to the steep north-south gradient of endemism. Endemic species are concentrated in southern countries due to the historical role of these areas as glacial refugia (Hewitt 1999, Jansson 2003, Svenning and Skov 2007b). Northern countries have the widely distributed species that have left their glacial refugia and reached more or less northern latitudes due to the current environmental gradient, but southern countries have these same species plus the ones that have not abandoned their refugia. These endemics are responsible for a relevant part of turnover, and thus the scores of endemism covary with composition.

Although the effect on turnover patterns of uneven country areas is small, with the pure effect being negligible, as shown in the results, it was necessary to control for area variation in the analysis. Taking into account environmental variables, the relationship of annual precipitation with variation in faunal composition is remarkable, contrary to its null influence on richness or endemism. But, consequently, this relationship between turnover and precipitation explains the covariation between richness and range of precipitation. However, one of the most striking results is the relative importance of the independent effect of geographic position, as was also found for Iberian leaf beetles (Baselga and Jiménez-Valverde 2007). Contrary to richness, turnover varies with longitude in addition to latitude. Therefore, endemism in southern countries causes higher rates of turnover than those found in northern countries (Baselga 2007), but this longitudinal turnover does not generate (or covary with) the richness gradients. The large purely spatial fraction implies that present climatic conditions alone do not seem to be sufficient to explain geographical beta-diversity patterns of European longhorn beetles. Of course, the pure geographic fraction may contain environmental structure from unmeasured environmental variables, but such unmeasured climatic variables probably have little relevance considering the high number of climatic factors used in this study. Therefore, it seems that although richness is determined by a combined climatic-geographic gradient, turnover, in contrast, is driven by both independent effects of climate and geographic constraints that must be accounting for dispersal limitation or stochastic colonization events. In other words, the processes controlling the richness attained in each area seems to be more deterministic than the processes that influence species composition.

Acknowledgements - I wish to thank Mikhail Danilevsky for making freely available the check-list of European Cerambycidae, Alberto Jiménez-Valverde, and Jorge M. Lobo for valuable comments on the manuscript, and three anonymous referees for interesting suggestions and criticisms. $\mathrm{AB}$ position at MNCN is supported by MEC Juan de la Cierva Program.

\section{References}

Araujo, M. B. and Pearson, R. G. 2005. Equilibrium of species' distributions with climate. - Ecography 28: 693-695.

Baselga, A. 2007. Disentangling distance decay of similarity from richness gradients: response to Soininen et al. 2007. - Ecography 30: 839-842.

Baselga, A. and Jiménez-Valverde, A. 2007. Environmental and geographical determinants of beta diversity of leaf beetles (Coleoptera: Chrysomelidae) in the Iberian Peninsula. - Ecol. Entomol. 32: 312-318.

Blackburn, T. M. and Gaston, K. J. 2002. Scale in macroecology. - Global Ecol. Biogeogr. 11: 185-189.

Borcard, D. et al. 1992. Partialling out the spatial component of ecological variation. - Ecology 73: 1045-1055.

Clark Labs 2000. Idrisi 32.02. - GIS software package.

Currie, D. J. et al. 2004. Predictions and tests of climate-based hypotheses of broad-scale variation in taxonomic richness. - Ecol. Lett. 7: 1121-1134.

Danilevsky, M. L. 2007. A check-list of longicorn beetles (Coleoptera, Cerambycoidea) of Europe. $-<$ www.cerambycidae. narod.ru $>$.

Dennis, R. L. H. et al. 1998. Faunal structures among European butterflies: evolutionary implications of bias for geography, endemism and taxonomic affiliation. - Ecography 21: 181203.

Erwin, T. L. 1991. How many species are there - revisited. - Conserv. Biol. 5: 330-333.

Evans, K. L. and Gaston, K. J. 2005. Can the evolutionary-rates hypothesis explain species-energy relationships? - Funct. Ecol. 19: 899-915.

Gaston, K. J. 1991. The magnitude of global insect species richness. - Conserv. Biol. 5: 283-296.

Graham, C. H. 2006. Habitat history improves prediction of biodiversity in rainforest fauna. - Proc. Nat. Acad. Sci. USA 103: 632-636.

Habel, J. C. et al. 2005. The fourth paradigm pattern of postglacial range expansion of European terrestrial species: the phylogeography of the marbled white butterfly (Satyrinae, Lepidoptera). - J. Biogeogr. 32: 1489-1497.

Hawkins, B. A. and Porter, E. E. 2003. Water-energy balance and the geographic pattern of species richness of western Palearctic butterflies. - Ecol. Entomol. 28: 678-686.

Hawkins, B. A. et al. 2003. Energy, water, and broad-scale geographic patterns of species richness. - Ecology 84: 31053117.

Hawkins, B. A. et al. 2006. Post-Eocene climate change, niche conservatism, and the latitudinal diversity gradient of $\mathrm{New}$ World birds. - J. Biogeogr. 33: 770-780.

Hewitt, G. M. 1999. Post-glacial re-colonization of European biota. - Biol. J. Linn. Soc. 68: 87-112.

Hewitt, G. M. 2004. Genetic consequences of climatic oscillations in the Quaternary. - Phil. Trans. R. Soc. B 359: 183-195. 
Hijmans, R. J. et al. 2005. Very high resolution interpolated climate surfaces for global land areas. - Int. J. Climatol. 25: 1965-1978.

Hillebrand, H. 2004. On the generality of the latitudinal diversity gradient. - Am. Nat. 163: 192-211.

Hood, G. M. 2006. PopTools version 2.7.5. - < http:// www.cse.csiro.au/poptools $>$.

Jansson, R. 2003. Global patterns in endemism explained by past climatic change. - Proc. R. Soc. B 270: 583-590.

Koleff, P. et al. 2003. Measuring beta diversity for presenceabsence data. - J. Anim. Ecol. 72: 367-382.

Legendre, P. and Legendre, L. 1998. Numerical ecology, 2nd ed. - Elsevier.

Legendre, P. et al. 2005. Analyzing beta diversity: partitioning the spatial variation of community composition data. - Ecol. Monogr. 75: 435-450.

Lobo, J. M. et al. 2002. Modelling the species richness distribution of French dung beetles (Coleoptera, Scarabaeidae) and delimiting the predictive capacity of different groups of explanatory variables. - Global Ecol. Biogeogr. 11: 265-277.

Lumaret, J. P. and Lobo, J. M. 1996. Geographic distribution of endemic dung beetles (Coleoptera, Scarabaeoidea) in the western Palaearctic region. - Biodiv. Lett. 3: 192-199.

Mittelbach, G. G. et al. 2007. Evolution and the latitudinal diversity gradient: speciation, extinction and biogeography. - Ecol. Lett. 10: 315-331.

Montoya, D. et al. 2007. Contemporary richness of holarctic trees and the historical pattern of glacial retreat. - Ecography 30: 173-182.

O'Brien, E. M. 2006. Biological relativity to water-energy dynamics. - J. Biogeogr. 33: 1868-1888.

Odegaard, F. 2000. How many species of arthropods? Erwin's estimate revised. - Biol. J. Linn. Soc. 71: 583-597.

Oksanen, J. et al. 2007. vegan: community ecology package. R package version 1.8-5. $-<$ http://cran.r-project.org/ $>$.

Qian, H. et al. 2005. Beta diversity of angiosperms in temperate floras of eastern Asia and eastern North America. - Ecol. Lett. 8: $15-22$.

R Development Core Team 2006. R: a language and environment for statistical computing. $-<$ http://www.r-project.org $>$.

Rahbek, C. and Graves, G. R. 2001. Multiscale assessment of patterns of avian species richness. - Proc. Nat. Acad. Sci. USA 98: 4534-4539.

Ribera, I. and Vogler, A. P. 2004. Speciation of Iberian diving beetles in Pleistocene refugia (Coleoptera, Dytiscidae). - Mol. Ecol. 13: 179-193.

Rodríguez, M. A. et al. 2005. Energy, water and large-scale patterns of reptile and amphibian species richness in Europe. - Acta Oecol. 28: 65-70.

Download the Supplementary material as file E5335 from $<$ www.oikos.ekol.lu.se/appendix >.
Rodríguez, M. A. et al. 2006. The geographic distribution of mammal body size in Europe. - Global Ecol. Biogeogr. 15: 173-181.

Rodríguez, P. and Arita, H. T. 2004. Beta diversity and latitude in North American mammals: testing the hypothesis of covariation. - Ecography 27: 547-556.

Soininen, J. et al. 2007. The distance decay of similarity in ecological communities. - Ecography 30: 3-12.

Storch, D. et al. 2006. Energy, range dynamics and global species richness patterns: reconciling mid-domain effects and environmental determinants of avian diversity. - Ecol. Lett. 9: 13081320.

Svenning, J. C. and Skov, F. 2007a. Could the tree diversity pattern in Europe be generated by postglacial dispersal limitation? - Ecol. Lett. 10: 453-460.

Svenning, J. C. and Skov, F. 2007b. Ice age legacies in the geographical distribution of tree species richness in Europe. - Global Ecol. Biogeogr. 16: 234-245.

Tribsch, A. 2004. Areas of endemism of vascular plants in the eastern Alps in relation to Pleistocene glaciation. - J. Biogeogr. 31: 747-760.

Tuomisto, H. and Ruokolainen, K. 2006. Analyzing or explaining beta diversity? Understanding the targets of different methods of analysis. - Ecology 87: 2697-2708.

Tuomisto, H. et al. 2003. Dispersal, environment, and floristic variation of western Amazonian forests. - Science 299: 241244.

Whittaker, R. J. et al. 2001. Scale and species richness: towards a general, hierarchical theory of species diversity. - J. Biogeogr. 28: 453-470.

Whittaker, R. J. et al. 2007. Geographical gradients of species richness: a test of the water-energy conjecture of Hawkins et al. (2003) using European data for five taxa. - Global Ecol. Biogeogr. 16: 76-89.

Williams, P. H. et al. 1999. Interpreting biogeographical boundaries among Afrotropical birds: spatial patterns in richness gradients and species replacement. - J. Biogeogr. 26: 459-474.

Willig, M. R. et al. 2003. Latitudinal gradients of biodiversity: pattern, process, scale, and synthesis. - Annu. Rev. Ecol. Evol. Syst. 34: 273-309.

Willis, K. J. and Niklas, K. J. 2004. The role of Quaternary environmental change in plant macroevolution: the exception or the rule? - Phil. Trans. R. Soc. B 359: 159-172.

Wilson, M. V. and Shmida, A. 1984. Measuring beta diversity with presence absence data. - J. Ecol. 72: 1055-1064.

Wolters, V. et al. 2006. Relationship among the species richness of different taxa. - Ecology 87: 1886-1895. 